are from both physiologists and biochemists working in this field, and cover ion transport across cell membranes of many kinds such as erythrocytes, frog skin, nerve, muscle and yeast cells. For the non-specialist reader with an interest in the subject as it applies in the human body the going is rather heavy, and complete understanding requires a knowledge of mathematics and thermodynamics. However much interesting information may be gleaned. The paper by A. Rothstein on the inorganic ion content of yeast cells is particularly clear, perhaps because in this subject the study of the transport of cations is not confused by variable cell permeability to anions (except phosphate). Medical readers may find the discussion of the effect of cardiac glycosides on the sodium and potassium pump mechanism of both practical and theoretical interest. As to the mechanism of the pump, little new information emerges, but some very elegant experiments have been performed.

This book should be read by all those interested in cell membrane ion transfer, knowledge of which can, of course, be applied to diabetic coma, the effect of such drugs as digitalis and steroids, treatment of hyperkalæmia, and the so-called 'sick-cell syndrome', to mention only a few clinical conditions.

\section{Anæsthetic Accidents}

V. Keating, M.B., B.CH., D.A., F.F.A.R.C.S. Second edition. Pp. viii +288 . London: Lloyd Luke. 196r. 28s.

This is the second edition of a book which has now become quite well known, and the author is to be congratulated on producing a most useful compendium of information on the complications of general and regional anæsthesia. The book is essentially non-specialized, and many complications peculiar to thoracic, cardiac and neuro-surgical anæsthesia are not discussed. Although, generally speaking, the lay-out is good, the chapter headings do not cover hepatic and renal complications, and these are not specifically dealt with.

A good deal of physiological information is included in the text, but although this is useful one wonders whether more space might not have been devoted to what is, after all, the real subject-matter: the section on ophthalmic complications, for example, is very sketchy (do chloroform burns no longer deserve a mention?), and very little is said about the potential dangers of the conventional anæsthetic machine. The section on convulsions could do with bringing up to date, and it is disappointing to see that the lateral position is still advocated only for patients who have undergone ENT operations-surely this should be the routine position for all patients returning to the ward. It is also a little surprising to find $5 \%$ thiopentone referred to as though it were still the standard dilute solution, and the difference between this and the $2.5 \%$ solution, as far as intra-arterial injection is concerned, is not sufficiently stressed.

Exception might be taken to the implication on page 275 that ampoules should be kept in their original box since their labels are often impossible to read. Surely, the only thing to do when a label is illegible is throw the ampoule away! The author suggests that a colour code system for dangerous drugs is badly needed: perhaps a better alternative would be to ensure that all ampoules are of a standard size and shape, so as to be indistinguishable unless the etching is read every time.

All these are minor criticisms of a well-written book which deserves a place on the shelf of every practising anæsthetist.
Lipids and the Steroid Hormones in Clinical Medicine

Proceedings of an Applied Seminar of the Association of Clinical Scientists. Editors: F. WILlIAM Sunderman, M.D., PH.D., SC.D.; F. William Sustoerman; Jnr., M.D. Pp. ix +205 , illustrated. Philadelphia and Montreal: J. B. Lippincott Company. 196r. 85s.

This book represents the edited proceedings of a seminar on lipids and the steroid hormones organized by the Association of Clinical Scientists. Seventeen lecturers, in addition to the two editors, are authors of the individual chapters.

The first part of the book deals with the lipids; after a short introduction on their classification there follows a series of chapters on the extraction and determination of the lipids, cholesterol and cholesterol esters in serum. Later chapters deal with methods for total and free fatty acids in serum and lipoproteins in serum. Here there is an interesting chapter on the clinical significance of these findings, with special relation to atherogenesis, and cardiovascular disease.

In a summary on the clinical interpretation of lipid values in the fæces no mention is made of the importance of a relatively high intake of fat prior to the collection of specimens and it is difficult to agree with the statement that fat balance studies are 'mainly of research interest'

The second half of the book deals with the steroids and after a lecture on their fundamental chemical consideration there follow sections on chromatographic fractionation of urines, their colorimetric reactions and estimations, partition chromatography of steroids, and the use of radioisotopes in steroid chemistry.

This is followed by a description of methods for the estimation of urinary 17 -ketosteroids and 17 -hydroxycorticoids. There is a short final chapter on the clinical ? significance of œstrogen and progesterone estimations.

This is essentially a book for the specialist chemical pathologist dealing as it does largely with techniques (or should we say methodology) or for the trainee in this subject. One should also say that the techniques are described in far greater detail than is required by most workers in English laboratories.

\section{Essentials of Orthopadics}

Philip Wiles. Third edition. Pp. xiii +572 , illustrated. London: J. \& A. Churchill. 1960. 70s.

The temptation of the author who brings an already standard work up to date is simply to add any new advances piecemeal to his text; the result, all too often, is a jumble in which successive editions come to resemble archæological sites. Mr. Wiles has firmly resisted this temptation. Where new ideas have been sufficiently tested to be incorporated in the body of orthopædic thought, he has built them into his main discussion and not relegated them to the indignity of mere footnotes. To do this without unduly enlarging his text has meant cutting out dead wood, a difficult process in which he has once again shown his skill as a teacher.

All orthopædic surgeons and many students are already familiar with the book; it has become an old and trusted friend. They need not fear that in this new edition it has lost its distinctive character. The arrangement is unchanged, with the early emphasis on postural defects and back pain, followed by regional orthopædics in which the disorders are considered part by part, and finally an account is given of general orthopædic disorders. 